\title{
The effects of delivery type and gender on intraocular pressure and central corneal thickness in newborns
}

\author{
Os efeitos do tipo de parto e sexo sobre a pressão intraocular e espessura corneana central em \\ recém-nascidos
}

Zeynep Gursel Ozkurt ${ }^{1}$, Selahattin Balsak ${ }^{2}$, Berrin Balsak ${ }^{3}$, Hande Guclu ${ }^{4}$, Muhammed Sahin ${ }^{1}$, Harun Yuksel ${ }^{1}$, Fatih M. Turkcu ${ }^{1}$

\begin{abstract}
Purpose: To analyze intraocular pressure (IOP) and central corneal thickness (CCT) in newborns during the first $12 \mathrm{~h}$ of life.

Methods: Forty-three newborns born by vaginal delivery (VD) and 30 newborns born by cesarean section (CS) were evaluated. IOP and CCT were measured using Tono-Pen and handheld pachymeter, respectively, at both the $5^{\text {th }}$ minute after delivery and at the $12^{\text {th }} \mathrm{h}$ of life.

Results: The mean IOP for the VD group was significantly higher than that of the CS group at both the $5^{\text {th }}$ minute and $12^{\text {th }} h$ ( $p=0.042$ and $p=0.018$, respectively). In both groups, the IOP decreased by the $12^{\text {th }} \mathrm{h}$, but the decrease was only significant for the CS group $(p=0.020)$. The decrease in CCT over the $12 \mathrm{~h}$ was significant for both groups $(p<0.001)$. In the VD and CS groups, the IOP values of the males were significantly higher than those of the females at the fifth minute only ( $p=0.024$ and $p=0.043$, respectively). No other values were significantly different between the genders.

Conclusions: Newborn IOP is affected by the mode of delivery and gender. A higher IOP was found in vaginally delivered newborns than in CS newborns for at least $12 \mathrm{~h}$ postpartum. CCT showed a significant decline within $12 \mathrm{~h}$. Male newborns have significantly higher IOP values in the first minutes of life.
\end{abstract}

Keywords: Cesarean section; Delivery, obstetric; Intraocular pressure; Cornea/anatomy \& histology; Infant; Newborn

\section{RESUMO}

Objetivos: Analisar a pressão intraocular (IOP) e a espessura corneana central (CCT) em recém-nascidos durante as primeiras 12 horas de vida.

Método: Quarenta e três recém-nascidos nascidos por parto vaginal (VD) e 30 recém-nascidos nascidos após cesariana (CS) foram avaliados. IOPe CCTforam medidos com Tono-Pen e Handheld Pachymeter no quinto minuto após o parto e na décima segunda hora de vida.

Resultados: A média de IOP para o grupo VD foi significativamente maior do que o grupo CS tanto no quinto minuto quanto na décima segunda hora $(p=0,042, p=0,018$ respectivamente). Em ambos os grupos, a IOP diminuiu na décima segunda hora, mas a redução foi significativa apenas para o grupo CS $(p=0,020)$. A diminuição da CCT nas doze horas foi significativa para ambos os grupos $(p<0,001)$. Nos grupos VD e CS os valores de IOP dos homens foram significativamente maiores do que das mulheres apenas no quinto minuto ( $p=0,024$ e $p=0,043$, respectivamente). Outros valores não foram significativamente diferentes entre os sexos.

Conclusões: A IOP em recém-nascidos é afetada pela via de parto e pelo sexo. A IOP é maior em recém-nascidos de parto normal durante pelo menos 12 horas. A CCT mostra queda significativa no prazo de 12 horas. Recém-nascidos do sexo masculino têm valores de IOP significativamente mais elevados nos primeiros minutos de vida.

Descritores: Cesárea; Parto obstétrico; Pressão intraocular; Córnealanatomia \& histologia; Recém-nascido

\section{INTRODUCTION}

Intraocular pressure (IOP) and central corneal thickness (CCT) have been measured in term and pre-term newborns in previous studies, and are well-documented ${ }^{(1-5)}$. However, no data are available on the effect of the mode of delivery on IOP and CCT or on the changes in these in the first hours of life. Birth itself, and particularly the duration of active labor until vaginal delivery (VD), is the main stressor for the infant during the peripartum period ${ }^{(6)}$. This stress results in higher plasma catecholamine levels, grades of excitability, and heart rates in vaginally delivered infants ${ }^{(7-9)}$. In previous adult and animal studies, physical and emotional stress have also been shown to induce elevation in IOP(10-11). Thus, IOP in vaginally-delivered infants might also be affected by delivery stress.

CCT in newborns decreases during the first days of life ${ }^{(1,2)}$, and the corneal endothelium is primarily responsible for the pump function.
Previous studies of mouse corneas have demonstrated that the pump function of the corneal endothelium can be enhanced by dexamethasone ${ }^{(12,13)}$. During VD, stress increases the plasma levels of catecholamines ${ }^{(14-16)}$. This increment may also activate the corneal endothelial pump system and result in thinner corneas in vaginally-delivered infants. The effect of gender on CCT in newborns has been evaluated previously, and corneas in male newborns have been found to be thicker than corneas in female newborns ${ }^{(1)}$. However, the effect of gender on IOP and CCT in the first hours of life has not been analyzed.

The gold standard for IOP measurement is Goldmann applanation tonometry, and in many studies the measured IOP has been demonstrated to vary with $\mathrm{CC}^{(17-19)}$. In recent studies, Tono-Pen $\mathrm{XL}$ and iCare have been recommended for obtaining accurate IOP measurements of edematous corneas ${ }^{(20)}$. These methods were presumed to be less dependent on CCT due to the smaller area of applanation ${ }^{(21)}$.
Submitted for publication: August 24, 2015

Accepted for publication: January 14, 2016

Ophthalmology Department, Dicle University of Medicine, Diyarbakir, Turkey.

Diyarbakir Education and Research Hospital, Diyarbakir, Turkey.

Obstetrics and Gynecology Department, Diyarbakir Women's and Children's Diseases Hospital,

Diyarbakir, Turkey.

${ }^{4}$ Ophthalmology Department, Trakya University of Medicine, Edirne, Turkey.
Funding: No specific financial support was available for this study.

Disclosure of potential conflicts of interest: None of the authors have any potential conflicts of interest to disclose.

Corresponding author: Zeynep Gursel Ozkur. E-mail: drzeynepgursel@gmail.com

Approved by the following research ethics committee: Dicle University Medical Faculty Ethics Committee for Non-Interventional Studies (August 27, 2013 \#474). 
In newborns, corneas are edematous, so the Tono-Pen is a suitable instrument for measuring IOP.

In this study, we prospectively studied the behavior of IOP and CCT in newborns in terms of their delivery type and gender. Our aim was to establish a standard of normality of IOP and CCT of newborns in the first $12 \mathrm{~h}$ of their lives.

\section{METHODS}

This study was approved by the institutional review board of the hospital, and adhered to the tenets of the Declaration of Helsinki. In this prospective study, 43 right eyes of 43 infants born by VD and 30 right eyes of 30 infants born after elective cesarean section (CS) by epidural anesthesia at Diyarbakir Women's and Children's Diseases Hospital, were evaluated. Parental consent was obtained after the purpose and risks of the study had been fully explained.

The inclusion criteria included: infants with a gestational age between 37 and 41 weeks according to Dubowitz assessment (a method of clinical assessment in newborns from birth until five days old that includes neurological criteria for the infant's maturity and other physical criteria to determine gestational age), and with a birth weight between $2500 \mathrm{~g}$ and $4000 \mathrm{~g}$. Further, in the VD group, infants presented cephalically, and in the CS group, infants born after elective operations, were included. The exclusion criteria were as follows: ocular abnormalities resulting in a negative red reflex; corneal and iris alterations; familial congenital glaucoma; maternal major organ dysfunction or a syndrome that can affect IOP; and complicated or assisted deliveries, general anesthesia, and the mother being given anesthetic drugs in addition to epidural anesthesia.

The ophthalmological examination included an external examination, testing of pupil reactivity, and visualization of the red reflex. Measurements were performed using the smallest wire lid speculum under topical anesthesia (proparacaine hydrochloride $0.5 \%$ ) in a supine position. The right eyes of all the newborns were measured by the same operator. The newborn was given time to become accustomed to the speculum (quiet and still) to avoid a Valsalva-like effect. IOP and CCT were measured centrally immediately after the delivery at the fifth minute and at the $12^{\text {th }} \mathrm{h}$ of the postpartum period. IOP was determined using the Tono-Pen AVIA (TPA; Reichert Inc., Depew, NY, USA). The TPA displays the mean of 10 independent readings, along with a statistical confidence index. Each series of measurements was performed three times, and the mean was taken into account. The mean of the measurements was accepted with a confidence index of $95 \%$, which represents very reliable measurements. CCT was determined using the Palm Scan AP2000 Handheld Pachymeter (Micromedical Devices, Inc., Englewood, CO, USA), by determining the mean of four independent readings.

Statistical calculations were performed using the SPSS 15.0 statistical package (SPSS for Windows, Chicago, IL, USA). All data are presented as the mean \pm standard deviation. The distribution of the data was analyzed using the Kolmogorov-Smirnov test, and the distributions of IOP and CCT were found to be normal; therefore, parametric tests were used. Qualitative data were evaluated using the paired samples t-test and the independent samples t-test. The Pearson test was used for correlation analysis, and a $p$-value of $<0.05$ was regarded as statistically significant.

\section{RESULTS}

In this study, 43 right eyes of 43 infants (28 girls, 15 boys, ratio: 1.86) born by VD and 30 right eyes of 30 infants (18 girls, 12 boys, ratio: 1.5) born by CS, were evaluated. In the VD group, the mean gestational age at birth was $38.4 \pm 0.63$ weeks (range: $37-41$ weeks), and the mean birth weight was $3199 \pm 329 \mathrm{~g}$ (range: $2700-3900 \mathrm{~g}$ ). In the CS group, the mean gestational age at birth was $38.4 \pm 0.62$ weeks (range: 37-40 weeks), and the mean birth weight was $3290 \pm 349 \mathrm{~g}$ (range: $2770-4000 \mathrm{~g}$ ). Differences between the two groups in terms of gestational age, birth weight, and gender were not statistically significant ( $p=0.957, p=0.388$, and $p=0.656$, respectively). The mean IOP and CCT values for both groups at the fifth minute and at the $12^{\text {th }} \mathrm{h}$ of the postpartum period are shown in table 1. The independent samples $t$-test was used to compare the IOP and CCT values between the VD and CS groups. The IOP values of the VD group were significantly higher than those of the CS group, both at the fifth minute and at the $12^{\text {th }} \mathrm{h}$ of the postpartum period ( $p=0.042$ and $p=0.018$, respectively). In the CS group, the IOPs of five newborns were above $21 \mathrm{mmHg}$ at the fifth minute (range: $31-23 \mathrm{mmHg}$ ), and the IOP of two of these infants (40\%) remained above $21 \mathrm{mmHg}$ at the $12^{\text {th }} \mathrm{h}$ ( 23 and $28 \mathrm{mmHg}$ ). In the VD group, the IOPs of 16 newborns were above $21 \mathrm{mmHg}$ at the fifth minute (range: $43-22 \mathrm{mmHg}$ ), and the IOP of five of these infants $(31.25 \%)$ remained above $21 \mathrm{mmHg}$ at the $12^{\text {th }} \mathrm{h}$ (range: $35-22 \mathrm{mmHg}$ ). The CCT differences between the two groups were not statistically significant ( $p=0.188$ and $p=0.075$, respectively). We analyzed the changes in IOP and CCT between the fifth minute and $12^{\text {th }} \mathrm{h}$ in both groups, using the paired samples $t$-test. The CCT values for both the VD and CS groups declined significantly $(p<0.001$ for both groups). In the VD group, the IOP appeared to be decreased, but the difference was not statistically significant $(p=0.120)$. Conversely, IOP decreased significantly in the CS group $(p=0.020)$. We analyzed the correlations between the IOP and CCT values in both delivery groups at both measurement times. In the VD group, a weak correlation was found at the fifth minute and $12^{\text {th }} \mathrm{h}$ ( $p=0.006, r=0.416$ and $p=0.000, r=0.538$, respectively). However, in the CS group, no correlation was found at the fifth minute and $12^{\text {th }} \mathrm{h}(p=0.870, r=-0.031$ and $p=0.665, r=0.082$, respectively).

In the VD and CS groups, we also evaluated the effect of gender on IOP and CCT both at the fifth minute and at the $12^{\text {th }} \mathrm{h}$ of the postpartum period. The VD group values are shown in table 2, while the CS group values are shown in table 3. In the VD and CS groups, the IOP values of the males were significantly higher than those of the females at the fifth minute ( $p=0.024$ and $p=0.043$, respectively). When the delivery type was not taken into account, at the fifth minute all of the males' IOP was again significantly higher than that of the females ( $p=0.003)$. In the VD and CS groups, at the fifth minute, the CCT values of the males were not significantly different to those of the females ( $p=0.091$ and $p=0.841$, respectively). Further, when the delivery

Table 1. IOP and CCT values of the VD- and CS-delivery groups at the fifth minute and at the $12^{\text {th }}$ hour of the postpartum period

\begin{tabular}{|c|c|c|c|c|c|c|}
\hline Measurement time & Delivery type & Newborn numbers & Mean IOP \pm SD $(\mathrm{mmHg})$ & IOP range $(\mathrm{mmHg})$ & Mean CCT $\pm S D(\mu \mathrm{m})$ & CCT range $(\mu \mathrm{m})$ \\
\hline \multirow[t]{2}{*}{$5^{\text {th }} \min$} & VD & 43 & $21.6 \pm 6.2$ & $13-45$ & $681 \pm 55$ & $535-789$ \\
\hline & CS & 30 & $18.9 \pm 4.6$ & $12-31$ & $703 \pm 86$ & $556-916$ \\
\hline \multirow[t]{2}{*}{$12^{\text {th }} \mathrm{h}$} & VD & 43 & $19.8 \pm 5.6$ & $11-35$ & $595 \pm 53$ & $510-721$ \\
\hline & CS & 30 & $16.9 \pm 4.2$ & $9-28$ & $623 \pm 80$ & $500-820$ \\
\hline
\end{tabular}

$\mathrm{IOP}=$ intraocular pressure; $\mathrm{CCT}=$ central corneal thickness; $\mathrm{VD}=$ vaginal delivery; $\mathrm{CS}=$ cesarean section; $\mathrm{SD}=$ standard deviation. 
Table 2. IOP and CCT values of both genders at the fifth minute and at the $12^{\text {th }} \mathrm{h}$ of the postpartum period in the VD group

\begin{tabular}{lcccccc}
\hline Measurement time & Gender & Newborn numbers & Mean IOP \pm SD $(\mathbf{m m H g})$ & IOP range $(\mathbf{m m H g})$ & Mean CCT \pm SD $(\boldsymbol{\mu m})$ & $\mathbf{C C T}$ range $(\boldsymbol{\mu m})$ \\
\hline $5^{\text {th }}$ min & Female & 28 & $20.1 \pm 5.1$ & $13-32$ & $670 \pm 51$ & $535-752$ \\
& Male & 15 & $24.5 \pm 7.0$ & $17-43$ & $700 \pm 58$ & $584-789$ \\
$12^{\text {th }} \mathrm{h}$ & Female & 28 & $19.3 \pm 5.0$ & $11-32$ & $582 \pm 42$ \\
& Male & 15 & $20.9 \pm 6.8$ & $12-35$ & $619 \pm 63$ \\
\hline
\end{tabular}

$\mathrm{IOP}=$ intraocular pressure; $\mathrm{CCT}=$ central corneal thickness; $\mathrm{SD}=$ standard deviation; $\mathrm{VD}=$ vaginal delivery.

Table 3. IOP and CCT values of both genders at the fifth minute and at the $12^{\text {th }} \mathbf{h}$ of the postpartum period in the CS group

\begin{tabular}{|c|c|c|c|c|c|c|}
\hline Measurement time & Gender & Newborn numbers & Mean IOP \pm SD $(\mathrm{mmHg})$ & IOP range $(\mathrm{mmHg})$ & Mean $\mathrm{CCT} \pm \mathrm{SD}(\mu \mathrm{m})$ & $\mathrm{CCT}$ range $(\mu \mathrm{m})$ \\
\hline \multirow[t]{2}{*}{$5^{\text {th }} \min$} & Female & 18 & $17.3 \pm 3.3$ & $12-25$ & $699 \pm 75$ & $556-916$ \\
\hline & Male & 12 & $21.1 \pm 5.4$ & $16-31$ & $705 \pm 94$ & $559-864$ \\
\hline \multirow[t]{2}{*}{$12^{\text {th }} \mathrm{h}$} & Female & 18 & $15.9 \pm 3.6$ & $12-23$ & $626 \pm 81$ & $513-820$ \\
\hline & Male & 12 & $18.4 \pm 4.7$ & $9-28$ & $618 \pm 82$ & $500-817$ \\
\hline
\end{tabular}

$\mathrm{IOP}=$ intraocular pressure; $\mathrm{CCT}=$ central corneal thickness; $\mathrm{SD}=$ standard deviation; $\mathrm{CS}=$ cesarean section.

type was not taken into account, there was no significant difference of the CCT values between the genders $(p=0.360)$. At the $12^{\text {th }} \mathrm{h}$, IOP values between the genders were not significantly different in the VD group, CS group, or in all of the studied newborns ( $p=0.386$, $p=0.107$, and $p=0.155$, respectively). Similarly, at the $12^{\text {th }} h$, the CCT values between the genders were not significantly different in the VD group, CS group, or all of the studied newborns ( $p=0.055, p=0.811$, and $p=0.225$, respectively).

\section{DISCUSSION}

In recent studies, IOP and CCT have been evaluated in pre-term and full-term newborns. However, to the best of our knowledge, CCT and IOP values immediately after birth and after $12 \mathrm{~h}$ have not been studied. Therefore, the current study is the first to report the effect of the mode of delivery and gender on IOP and CCT in the first $12 \mathrm{~h}$ of life.

Active labor is the main cause of stress for infants during the peripartum period(6). The final effectors of physical and emotional stresses during birth are glucocorticoids and the main actors are catecholamines such as adrenaline and noradrenaline. Previously published studies have shown that plasma catecholamine levels of infants born by CS are lower than those of infants born by VD ${ }^{(6,7)}$. Another study identified a significant correlation between a lower plasma level of noradrenaline and poor muscle tone and/or lower grade of excitability in infants born by CS compared to infants born by VD ${ }^{(8)}$. In the first minutes of life, higher heart rates have also been reported in infants born by VD compared to infants born by $\mathrm{CS}^{(9)}$. Psychological stress is known to induce elevated IOP in adults ${ }^{(10)}$. In our study, IOP values were significantly higher in the VD group than in the CS group at the fifth minute. The psychological stress of VD may be the cause of the higher IOP.

In the present study, IOP was also measured at the $12^{\text {th }} \mathrm{h}$ of the postpartum period. Although the IOP had decreased by the $12^{\text {th }} \mathrm{h}$ in both groups, the IOP values of the VD group were still significantly higher than those of the CS group. In a previous study, infant saliva cortisol levels were examined $72 \mathrm{~h}$ after birth, and higher levels were observed in the VD group than in the CS group ${ }^{(6)}$. The study demonstrated that the effects of delivery stress continue for at least $72 \mathrm{~h}$ postpartum. Therefore, the higher IOP in the VD group at the $12^{\text {th }} \mathrm{h}$ may have been the result of sustained higher cortisol levels.

Fetuses delivered vaginally are at greater risk of head compression than those delivered by CS. The direct physical effect of vaginal birth may be the reason for this increment in IOP. Further, the intracranial major venous system may be affected by the increased pressure around it due to the thin wall structure of the venous vessels. The effect of the mode of delivery on cerebral hemodynamics has been discussed in previous studies ${ }^{(22,23)}$. Moreover, similar changes of cerebral hemodynamics have been observed in newborns delivered by VD and $\mathrm{CS}^{(24)}$. Additionally, no correlation was found between the duration of labor and venous and arterial Doppler indices and velocities ${ }^{(25)}$. These data support our theory of hormonal effects on the IOP of newborns.

In our study, at the fifth minute, IOP of males was found to be significantly higher than that of females in both delivery groups. In a previous study, IOP was measured in 150 newborns between 12 and $24 \mathrm{~h}$ after birth, and again no significant difference was found between the genders ${ }^{(4)}$. This result is similar to the results of our study, because in our study the difference between the genders was only significant at the fifth minute. At the $12^{\text {th }} \mathrm{h}$, however, while the males' mean IOP values appeared to be higher than those of the females in both delivery groups, the differences were not statistically significant. As far as we know, none of the studies researching delivery stress, cerebral hemodynamics, and the IOP of newborns have evaluated the effect of gender. Further investigation is necessary to understand the reason for the higher IOP values in males.

Newborn CCT has also been evaluated in recent studies. The earliest measurements in the literature were performed at $6 \mathrm{~h}$ postpartum without grouping the newborns according to delivery type. The mean CCT was $647 \pm 61 \mu \mathrm{m}$ at 0-6 h postpartum and $611 \pm 72 \mu \mathrm{m}$ at $7-12 \mathrm{~h}$ postpartum ${ }^{(1)}$. For both groups, our results were higher than those of the previous study at 0-6 h postpartum, most likely due to our earlier measurement time. The effect of gender on the CCT of newborns was evaluated in the same study, at six days postpartum. In males, the mean CCT was $631 \pm 67 \mu \mathrm{m}$ in the right eyes and $630 \pm 65 \mu \mathrm{m}$ in the left eyes, while in females, these values were $601 \pm 52 \mu \mathrm{m}$ in the right eyes and $559 \pm 49 \mu \mathrm{m}$ in the left eyes; the difference between the genders was statistically significant ${ }^{(1)}$. In another study, 
the effect of gender was evaluated again at six days postpartum. The mean CCT of the males was again found to be higher than that of the females, but the difference was not significant ${ }^{(2)}$. In our study, although the differences did not reach statistical significance, in the VD group the males' mean CCT at both times was higher than that of the females. In the CS group, the differences between the genders were negligible. In the previous studies mentioned above, the delivery type was not taken into account. If the newborns had been grouped according to delivery type, the results could have been more significant in the VD groups.

Previous studies have reported a decline in CCT in newborns during the first days of life ${ }^{(1,2)}$. In our study, this decrease was highly significant in both the VD and CS groups. This decline is thought to be due to improving control of corneal hydration, evaporation, and corneal remodeling over time ${ }^{(2,5)}$. Prolonged eye closure may explain the thicker corneas during the first days of life. Infants are known to have physiologic intracellular fluid excess and, after birth, sudden fluid efflux occurs from the intracellular compartment to the extracellular compartment ${ }^{(26)}$. In addition to prolonged eye closure, physiologic intracellular fluid excess might be the cause of the edematous cornea.

The respiratory outcome in newborns is linked to fetal maturity and the mode of delivery. Infants delivered by CS have a higher incidence of respiratory distress than vaginally delivered infants. Active $\mathrm{Na}^{+}$transport across the pulmonary epithelium drives liquid from the lung lumen to the interstitium, and labor is critical for the activation of the $\mathrm{Na}^{+}$pump system. There is considerable evidence that high levels of endogenous catecholamines at birth may be important for accelerating alveolar fluid clearance by increasing its activity ${ }^{(27)}$. In our study, although the differences were not statistically significant, the mean CCT was higher for the CS group than for the VD group both at the fifth minute and at the $12^{\text {th }} \mathrm{h}$. The $\mathrm{Na}^{+}$- and $\mathrm{K}^{+}$-dependent ATPase $\left(\mathrm{Na}^{+} / \mathrm{K}^{+}\right.$-ATPase) expressed in the basolateral membrane of corneal endothelial cells is primarily responsible for the pump function of the corneal endothelium. In two different studies of mouse corneal endothelial cells, dexamethasone was shown to increase $\mathrm{Na}^{+} / \mathrm{K}^{+}$-ATPase activity and pump function ${ }^{(12,13)}$. We suggest that, like the pulmonary epithelium $\mathrm{Na}^{+}$transport system, the corneal endothelial pump function may be induced by higher endogenous plasma catecholamine levels in vaginally-delivered infants, causing thinner CCT values in the VD group than in the CS group.

To measure IOP and CCT in newborns, a protocol based on the experiences documented in previous studies was used. A previous study reported that the use of the Alfonso eyelid speculum in children can falsely elevate IOP by $4 \mathrm{mmHg}^{(28)}$. Further, topical anesthetics have been found to affect IOP and CCT readings ${ }^{(29,30)}$. Therefore, the use of a speculum and topical anesthetic drops are limitations of our study. The small number of cases involved in our study is another limitation. Since the international gold standard for IOP measurement is Goldmann applanation tonometry, the use of a Tono-Pen in our study could be considered a limitation. However, Tono-Pen XL and iCare have recently been recommended for obtaining accurate IOP measurements of edematous corneas ${ }^{(20)}$. These methods were presumed to be less dependent on CCT due to the smaller area of applanation ${ }^{(21)}$. The duration of active labor of the deliveries was not taken into account because, in our region, most pregnant women arrive at hospital after the beginning of active labor, which is another limitation of our study.

In conclusion, IOP remains higher in vaginally-delivered infants than in infants delivered by CS for at least $12 \mathrm{~h}$ postpartum. Infant CCT decreases significantly over the $12 \mathrm{~h}$ postpartum. Vaginally-delivered infants have thinner CCT values than infants delivered by CS. The present study establishes reference values for IOP and CCT in newborns, which could be used in the early diagnosis of congenital eye disorders. Additionally, these data may be useful for understanding the ocular physiology of newborns. Further studies are needed to clarify the possible effects on IOP and CCT in newborns.

\section{REFERENCES}

1. Rushood AA, Zahrani MH, Khamis A, Rushood AA. Central corneal thickness in full term Saudi newborns. Acta Ophthalmol. 2012;90(5):355-8.

2. Remón L, Cristóbal JA, Castillo J, Palomar T, Palomar A, Pérez J. Central and peripheral corneal thickness in full-term newborns by ultrasonic pachymetry. Invest Ophthalmol Vis Sci. 1992;33(11):3080-3.

3. Uva MG, Reibaldi M, Longo A, Avitabile T, Gangliano C, Scollo D, et al. Intraocular pressure and central corneal thickness in premature and full-term newborns. J AAPOS. 2011;15(4):367-9

4. Reddy SC, Alias R. Tono-pen measurement of intraocular pressure under topical anaesthesia in full term normal newborns. Int J Ophthalmol. 2014:7(1):92-4.

5. Kirwan C, O'Keefe M, Fitzsimon S. Central corneal thickness and corneal diameter in premature infants. Acta Ophthalmol Scand. 2005;83(6):751-3.

6. Schuller C, Känel N, Müller O, Kind AB, Tinner EM, Hösli I, et al. Stress and pain response of neonates after spontaneous birth and vacuum-assisted and cesarean delivery. Am J Obstet Gynecol. 2012;207(5):416-22.

7. Faxelius G, Lagercrantz H, Yao A. Sympathoadrenal activity and peripheral blood flow after birth: comparison in infants delivered vaginally and by caesarean section. J Pediatr. 1984;105(1):144-8.

8. Otamiri G, Berg G, Ledin T, Leijon I, Lagercrantz H. Delayed neurological adaptation in infants delivered by elective caesarean section and the relation to catecholamine levels. Early Hum Dev. 1991;26(1):51-60.

9. Dawson JA, Kamlin CO, Wong C, te Pas AB, Vento M, Cole TJ, et al. Changes in heart rate in the first minutes after birth. Arch Dis Child Fetal Neonatal Ed. 2010;95(3): 177-81.

10. Brody S, Erb C, Veit R, Rau H. Intraocular pressure changes: the influence of psychological stress and the Valsalva maneuver. Biol Psychol. 1999;51(1):43-57.

11. Miyazaki Y, MatsuoT, Kurabayashi Y. Immobilization stress induces elevation of intraocular pressure in rabbits. Ophthalmic Res. 2000;32(6):270-7.

12. Hatou S. Hormonal regulation of $\mathrm{Na}+/ \mathrm{K}+$-dependent ATPase activity and pump function in corneal endothelial cells. Cornea. 2011;30(10):60-6.

13. Hatou S, Yamada M, Mochizuki H, Shiraishi A, Joko T, Nishida T. The effects of dexamethasone on the Na,K-ATPase activity and pump function of corneal endothelial cells. Curr Eye Res. 2009;34(5):347-54.

14. VogI SE, Worda C, Egarter C, Bieglmayer C, Szekeres T, Huber J, et al. Mode of delivery is associated with maternal and fetal endocrine stress response. BJOG. 2006;113(4):441-5. Comment in: BJOG.2007;114(1):120-1.

15. Miller NM, Fisk NM, Modi N, Glover V. Stress responses at birth: determinants of cord arterial cortisol and links with cortisol response in infancy. BJOG. 2005;112(7):921-6.

16. Bergqvist LL, Katz-Salamon M, Hertegard S, Anand KJ, Lagercrantz H. Mode of delivery modulates physiological and behavioral responses to neonatal pain. J Perinatol. 2009; 29(1):44-50.

17. Li J, Herndon LW, Asrani SG, Stinnett S, Allingham RR. Clinical comparison of the proview eye pressure monitor with the Goldmann applanation tonometer and the Tonopen. Arch Ophthalmol. 2004;122(8):1117-21.

18. Lleo A, Marcos A, Calatayud M, Alonso L, Rahhal SM, Sanchis-Gimeno JA. The relationship between central corneal thickness and Goldmann applanation tonometry. Clin Exp Optom. 2003;86(2):104-8.

19. Shimmyo M, Ross AJ, Moy A, Mostafavi R. Intraocular pressure, Goldmann applanation tension, corneal thickness, and corneal curvature in Caucasians, Asians, Hispanics, and African Americans. Am J Ophthalmol. 2003;136(4):603-13.

20. Neuburger M, Maier P, Böhringer D, Reinhard T, F Jordan J. The impact of corneal edema on intraocular pressure measurements using goldmann applanation tonometry, Tono- Pen XL, iCare, and ORA: an in vitro model. J Glaucoma. 2013;22(7):584-90.

21. Hager A, Wiegand W. [Methods of measuring intraocular pressure independently of central corneal thickness]. Ophthalmologe. 2008;105(9):840-4. German.

22. Dubowitz LM, Dubowitz V, Palmer P, Verghote M. A new approach to the neurological assessment of the preterm and full-term newborn infant Brain Dev 1980:2(1):3-14.

23. Baytur YB, Tarhan S, Uyar Y, Ozcakir HT, Lacin S, Coban B, et al. Assessment of fetal cerebral arterial and venous blood flow before and after vaginal delivery or Cesarean section. Ultrasound Obstet Gynecol. 2004:24(5):522-8.

24. Dani C, Martelli E, Bertini G, Pezzati M, Rubaltelli FF. Haemodynamic changes in the brain after vaginal delivery and caesarean section in healthy term infants. BJOG. 2002; 109(2):202-6

25. Sihota R, Tuli D, Dada T, Gupta V, Sachdeva MM. Distribution and determinents of intraocular pressure in a normal pediatric population. Pediatr Ophthalmol Strabismus. 2006:43(1):14-8.

26. Aggarwal R, Deorari AK, Paul VK. Fluid and electrolyte management in term and preterm neonates. Indian J Pediatr. 2001;68(12):1139-42.

27. Jain L, Eaton DC. Physiology of fetal lung fluid clearance and the effect of labor. Semin Perinatol. 2006;30(1):34-43.

28. Epley KD, Tychsen L, Lueder GT. The effect of an eyelid speculum on intraocular pressure measurement in children. Am J Ophthalmol. 2002;134(6):926-7.

29. Almubrad TM, Ogbuehi KC. Clinical investigation of the effect of topical anesthesia on intraocular pressure. Clin Ophthalmol. 2007:1(3):305-9.

30. Nam SM, Lee HK, Kim EK, Seo KY. Comparison of corneal thickness after the instillation of topical anesthetics: proparacain eversus oxybuprocaine. Cornea. 2006;25(1):51-4. 